\title{
Cerebellar and extracerebellar involvement in mouse eyeblink conditioning: the ACDC model
}

\author{
Henk-Jan Boele ${ }^{1 t}$, Sebastiaan K. E. Koekkoek ${ }^{1 t}$ and Chris I. De Zeeuw ${ }^{1,2 * t}$ \\ Department of Neuroscience, Erasmus Medical Center, Rotterdam, The Netherlands \\ Netherlands Institute for Neuroscience, Royal Academy of Arts and Sciences, Amsterdam, The Netherlands
}

Edited by:

Egidio D'Angelo, University of Pavia, Italy

Reviewed by:

Yosef Yarom, Hebrew University, Israel

Egidio DAngelo, University of Pavia,

Italy

\section{*Correspondence}

Chris I. De Zeeuw, Department of

Neuroscience, Erasmus Medical

Center, Dr. Molewaterplein 50, P.O. box

1738, 3000 DR Rotterdam,

The Netherlands.

e-mail: c.dezeeuw@erasmusmc.nl

${ }^{+}$Henk-Jan Boele, Sebastiaan K. E.

Koekkoek and Chris I. De Zeeuw have

contributed equally to this work.
Over the past decade the advent of mouse transgenics has generated new perspectives on the study of cerebellar molecular mechanisms that are essential for eyeblink conditioning. However, it also appears that results from eyeblink conditioning experiments done in mice differ in some aspects from results previously obtained in other mammals. In this review article we will, based on studies using (cell-specific) mouse mutants and region-specific lesions, re-examine the general eyeblink behavior in mice and the neuro-anatomical circuits that might contribute to the different peaks in the conditioned eyeblink trace. We conclude that the learning process in mice has at least two stages: An early stage, which includes short-latency responses that are at least partly controlled by extracerebellar structures such as the amygdala, and a later stage, which is represented by well-timed conditioned responses that are mainly controlled by the pontocerebellar and olivocerebellar systems. We refer to this overall concept as the AmygdalaCerebellum-Dynamic-Conditioning Model (ACDC model).

Keywords: eyeblink conditioning, cued fear conditioning, mouse, amygdala, cerebellum, ACDC model

\section{INTRODUCTION}

Ever since Ivan Pavlov described the phenomenon of classical conditioning at the beginning of the 20th century (Pavlov, 1927), it has been widely used as a formalized training paradigm to study learning and memory formation. The simplicity of the paradigm is attractive: during training a behaviorally neutral stimulus, the conditioned stimulus (CS), is repeatedly followed by an unconditioned stimulus (US) that evokes a particular reflex, the unconditioned response (UR). This paired presentation of stimuli during training sessions gradually leads to the development of a conditioned response (CR), which is the reflex in response to the previously neutral CS. The pairings of the CS and US can occur in a delay or a trace conditioning paradigm. In a delay paradigm the CS precedes the US several hundred milliseconds and the stimuli temporally overlap and co-terminate. In a trace paradigm the CS is followed by a stimulus free interval before the US is presented (Pavlov, 1927).

One extensively studied form of classical conditioning is delay eyeblink conditioning. Work done in cats, rabbits, ferrets, and rats indicates that the cerebellum plays an essential role in eyeblink conditioning (see Eyeblink conditioning). The advent of mouse transgenics has opened up the possibility to further investigate the molecular and network mechanisms underlying eyeblink conditioning in a reproducible, conditional, and cell-specific fashion. Developments in transgenics have been particularly advantageous for cerebellar research because both the granule cells and the Purkinje cells can be manipulated with cell-specific promotors such as those for the GABA alpha6-subunit receptor (Luddens et al., 1990; McLean et al., 2000) and L7 (Oberdick et al., 1990; Barski et al., 2000). However, during more than 15 years of eyeblink conditioning in mice, it also appeared that several features of the conditioning process in mice differ from those in other mammals. Especially auditory startle reflexes and learned aspecific fear responses seem to be more prominent in the mouse eyeblink trace than in those of the other mammals. Until now these startle and fear responses seem to be neglected and are poorly described. However, before we can evaluate the contribution of specific cerebellar molecular mechanisms to the eyeblink conditioning learning process, a systematic description and unambiguous interpretation of these different peaks in the mouse eyeblink trace is required. In this review we will first evaluate the main studies that have identified the underlying circuitries of conditioned eyelid responses, auditory startle reflexes, and conditioned cued fear responses in mammals other than the mouse (part Neural Circuitries Underlying Delay Eyeblink Conditioning, Auditory Startle Reflexes, and Cued Fear Conditioning in Non-Murine Animals). Then, based on the characteristics of the responses in mice (parts Eyeblink Conditioning in Mice, Auditory Startle Reflexes in Mice and the Optimal CS for Eyeblink Conditioning, Cued Fear Conditioning in Mice and Similarities with Eyeblink Conditioning), we will propose how different networks, including the thalamo-amygdalar, pontocerebellar, and olivocerebellar systems, can contribute in an integrated fashion to different peaks in the conditioned mouse eyeblink trace (part The ACDC model: An Integrated Hypothesis of Eyeblink Conditioning in Mice).

\section{NEURAL CIRCUITRIES UNDERLYING DELAY EYEBLINK CONDITIONING, AUDITORY STARTLE REFLEXES, AND CUED FEAR CONDITIONING IN NON-MURINE ANIMALS EYEBLINK CONDITIONING}

During classical conditioning of the eyeblink and/or nictitating membrane response ${ }^{1}$ the CS is usually provided by an auditory tone and the US by a periocular electrical stimulation (Gormezano et al.,

\footnotetext{
${ }^{1}$ To enhance readability the term 'eyeblink conditioning' is used for both conditioning of the external eyelid response and nictitating membrane response.
} 
1962). In operant eyeblink conditioning the US is formed by a corneal air puff, which elicits a defensive eyeblink response. Repeated pairings of the tone and the electrical stimulation or corneal air puff will gradually result in a well-timed eyelid closure in response to the tone. Converging lines of evidence obtained in cats, rabbits, ferrets, and rats suggest a major role for the cerebellum in delay eyeblink conditioning (McCormick et al., 1981, 1982; Mauk et al., 1986; Yeo and Hardiman, 1992; Hesslow, 1994; Rasmussen et al., 2008). Briefly, the main neurocircuitries involved in mediating the CS and US include the pontocerebellar and olivocerebellar input systems, respectively (Figure 1A). The auditory CS signals are relayed via mossy fiber - parallel fiber projections from the lateral parts of the pontine nuclei to the Purkinje cells in the cerebellar cortex (Steinmetz et al., 1986, 1987; Tracy et al., 1998; Freeman and Rabinak, 2004; Cicirata et al., 2005), and to a lesser extent via mossy fiber collaterals to the interposed cerebellar nuclei (Dietrichs et al., 1983; Brodal et al., 1986; Parenti et al., 2002; Cicirata et al., 2005). The sensory trigeminal US signals on the other hand are relayed by climbing fibers from mainly the dorsal accessory inferior olive to the Purkinje cells and via climbing fiber collaterals to the interposed nuclei (McCormick et al., 1985; Yeo et al., 1985; Mauk et al., 1986; Gould et al., 1993; Ruigrok and Voogd, 2000). The CRpathway is formed by the interposed nuclei projections via the red nucleus to the brainstem nuclei that innervate the eyelid muscles. These nuclei include the facial nucleus, which activates the orbicularis oculi muscle (Morcuende et al., 2002), and the oculomotor nucleus, which simultaneously deactivates the levator palpebrae muscle (Trigo et al., 1999; Delgado-Garcia and Gruart, 2002, 2005). The eyelid UR usually has two components: One (R1) is mediated

FIGURE 1 | Neurocircuitries underlying eyeblink conditioning, auditory startle reflexes, and cued fear conditioning. (A) Neural circuits engaged during eyeblink conditioning. The mossy fiber CS-pathway (green) and climbing fiber US-pathway (blue) converge at the PCs in the cerebellar cortex and to a much lesser extent at the IN neurons. The CR-pathway (gray) is formed by the cerebellar output neurons and relayed via the RN to the FN and OMN, which innervate the eyelid muscles. (For simplicity only the eyelid innervation by the FN is depicted, see text for more details.) Conditioned induced plasticity at the PC and possibly also in the IN gradually leads to the establishment of an adequate CR. (B) Neural circuits engaged during auditory startle reflexes. The fastest route for transmission of acoustic input into motor output is from the $\mathrm{CrN}$ via the $\mathrm{PnC}$ to the motor neurons, including the $\mathrm{FN}$. In addition, multiple afferent systems including the LSO, VTN, DCN, and VCN excitate the giant $\mathrm{PnC}$ neurons. Amygdala activity directly controls the expression of the startle reflex by its projections to the PnC. (C) Neural circuits engaged during cued fear conditioning. The tone (CS) and electric foot shock (US) are relayed to the LA from thalamic and cortical regions of the auditory (green) and somatosensory (purple) systems, respectively. The LA directly and indirectly projects to the CE, which efferents (red) control the expression of the different aspects of the fear reaction. One or two paired trials induces efficient plasticity in the LA resulting in typical fear CRs including freezing, tachycardia, tachypneu, and facial responses. AC, Auditory cortex; CE, Central amygdala; CG, Central gray; CN, Cochlear nucleus; CrN, Cochlear root nucleus; CS, Conditioned stimulus; DCN, Dorsal cochlear nucleus; FN, Facial nucleus; GC, Granule cell; IN, Interposed nuclei; IO, Inferior olive; LA, Lateral amygdala; LH, Lateral hypothalamus; LSO, Lateral superior olive; MGB, Medial geniculate body of the thalamus; MN, Motor neurons; OMN Oculomotor Nucleus, PC, Purkinje cell; PIN, Posterior intralaminar nucleus of the thalamus; PN, Pontine nuclei; PnC, Caudal pontine reticular nucleus; PVN, Paraventricular hypothalamic nucleus ; RN, Red nucleus; SC, Somatosensory cortex; TrN, Trigeminal nerve nucleus; US, Unconditioned stimulus; VCN, Ventral cochlear nucleus; VTN, Ventrolateral tegmental nucleus. by the short loop from the trigeminal nerve and nucleus to the facial nucleus, while the other one (R2) is mediated by a superimposed loop through the reticular formation and/or cervical spinal cord (Holstege et al., 1986; Pellegrini et al., 1995; van Ham and Yeo, 1996a, b).

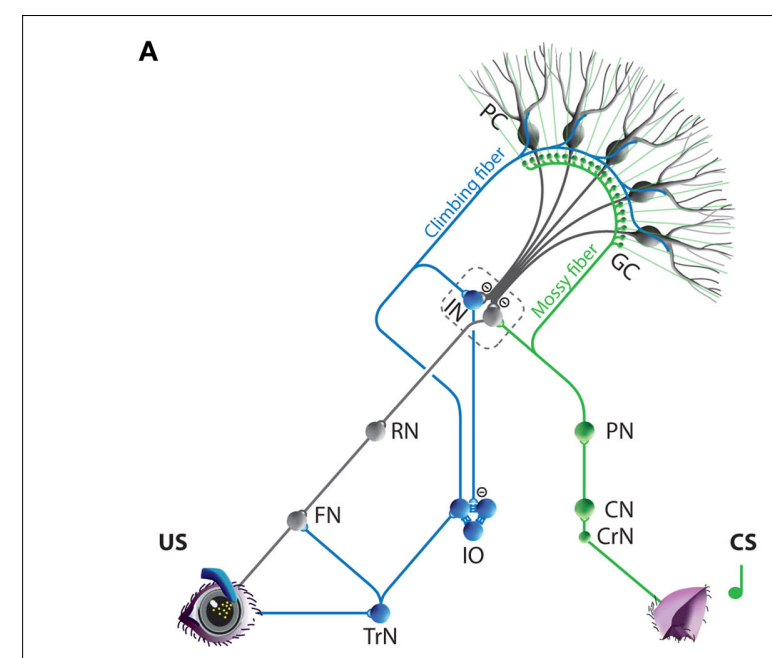

B
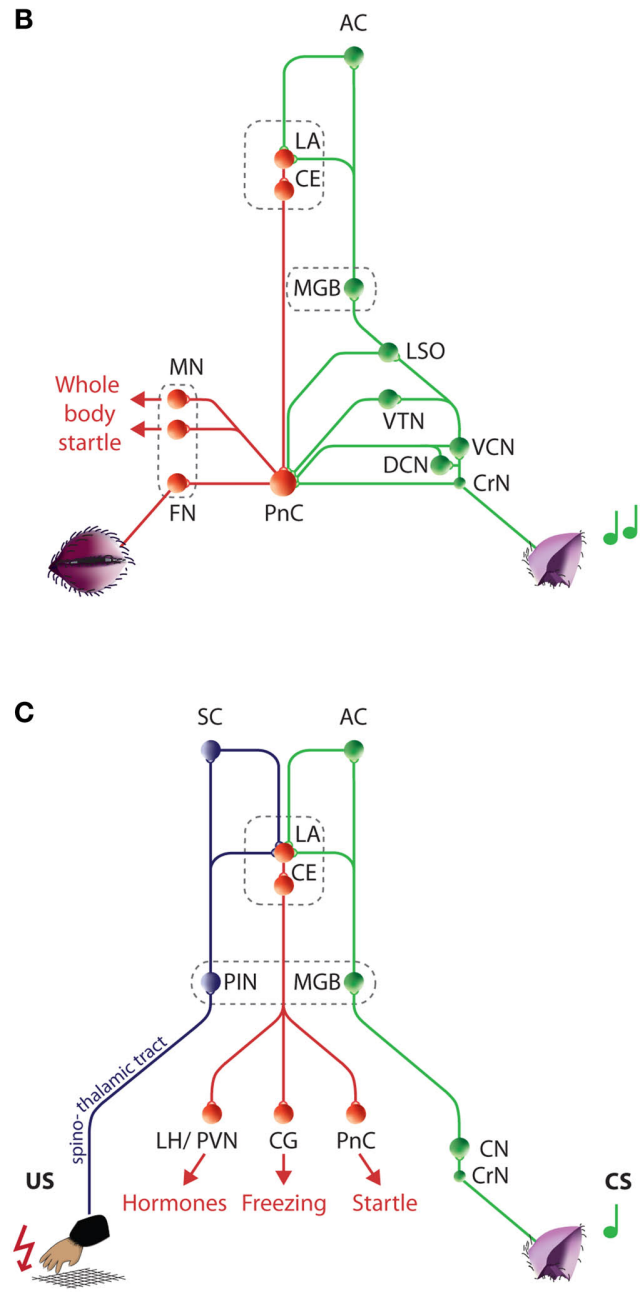
Even though the essential neuro-anatomical circuits underlying eyeblink conditioning are relatively well-described, the crucial plasticity mechanisms involved in the conditioning process are a matter in dispute. The classical site for plasticity is the cerebellar cortex (Marr, 1969; Albus, 1971; Ito et al., 1982). In cats, rabbits, and ferrets eyeblink controlling areas in the cerebellar cortex are clustered in lobule HVI, HVII, and the paramedian lobe (Yeo et al., 1985; Hesslow, 1994; Gruart et al., 1997; Yeo and Hesslow, 1998; Villarreal and Steinmetz, 2005; Svensson et al., 2006). Purkinje cell recordings in the $\mathrm{C} 3$ zone of lobule HVI in decerebrated ferrets during paired CS-US presentations clearly show the gradual development of a perfectly timed pause response in Purkinje cell simple spike and complex spike firing (Jirenhed et al., 2007; Rasmussen et al., 2008). This Purkinje cell pause disappears during extinction and reappears rapidly during reacquisition training. The plasticity processes at the Purkinje cell that causes this pause are still unknown. It seems unlikely that long-term depression (LTD) at the parallel fiber to Purkinje cell synapse is the sole underlying mechanism, because this mechanism is unable to explain the almost perfect timing of the Purkinje cell pause while varying the CS duration and thereby the CS-US co-termination. Even if the CS outlasts the used interstimulus interval (ISI) by several hundred milliseconds the Purkinje cell pause stops just after the expected US (Hesslow, personal communication). In line with this finding, Welsh et al. (2005) showed that pharmaceutical blockage of LTD in the rat cerebellar cortex does not prevent adaptation of the eyeblink CR timing after an ISI switch.

Lesions of the rabbit cerebellar cortex including all eyeblink controlling areas cannot completely abolish the expression of previously learned CRs. The timing, however, of the postlesion CRs is severely affected: Both onset and peak amplitude have a remarkable short latency (Perrett et al., 1993; Ohyama and Mauk, 2001; Ohyama et al., 2006). These postlesion CRs suggest additional sites of plasticity. One of these sites could be the cerebellar nuclei, because eyeblink conditioning induced plasticity in the interposed nuclei has been reported at both the systems physiological and morphological level (Perrett et al., 1993; Kleim et al., 2002; Ohyama et al., 2006; Weeks et al., 2007). The essential condition for this plasticity is convergence of the US and CS signals by climbing fibers and mossy fibers, respectively (Figure 1A). Climbing fibers originating from the dorsal accessory inferior olive indeed provide collaterals to the interposed nuclei (Ruigrok and Voogd, 2000). In contrast, mossy fiber projections from the pontine nuclei to the interposed nuclei are extremely sparse (Dietrichs et al., 1983; Brodal et al., 1986; Parenti et al., 2002; Cicirata et al., 2005). Therefore, their formation might be necessary to establish convergence of the CS and US in the interposed nuclei to support associative memory formation (Kleim et al., 2002; Ohyama et al., 2006). Interestingly, Delgado-Garcia and co-workers have demonstrated in freely moving cats that (posterior) interposed nuclei neurons (type A) start firing about $20 \mathrm{~ms}$ after CR onset. These data suggest that neuronal activity of the interposed nuclei cannot be causally related to the initiation of the CR. The main function of the cerebellum in eyeblink conditioning should be to establish a perfectly timed eyeblink CR by reinforcing the motor command and dampening the oscillations in the eyelid movement (Delgado-Garcia and Gruart, 2002, 2006). Instead, extracerebellar regions like the motor cortex or striatum might initiate the CRs (Aou et al., 1992; Gruart et al., 2000). Taken together, plasticity in the cerebellar cortex and nuclei seems to be responsible for different aspects of the learning process. According to the 'trigger-and-storage' model the initial encoding during training occurs in the Purkinje cells while the subsequent long-term memory is stored in the interposed nuclei (Medina et al., 2002). Others suggest that the cerebellar cortex influences the timing and amplitude of the CR, whereas the interposed nuclei are essential for the expression of CRs (Ohyama and Mauk, 2001).

Apart from the cerebellum, the hippocampus and amygdala are probably also involved in delay eyeblink conditioning. In rabbits, hippocampal pyramidal cells display learning related firing patterns that model the eyeblink CR (Berger and Thompson, 1978; Blankenship et al., 2005). The hippocampal neurons seem to encode more abstract aspects of the learning process like contextual and temporal information (Hoehler and Thompson, 1980; Kim and Fanselow, 1992; Lee and Kim, 2004). Interestingly, lesions of the hippocampus cannot abolish previously learned CRs and even seem to facilitate the learning in a delay eyeblink conditioning paradigm, which might be explained by a removal of hippocampal interference with the CS-US association in the cerebellum (Schmaltz and Theios, 1972; Lee and Kim, 2004).

The amygdala may serve to enhance the effectiveness of the CS and to influence the arousal during training. Weisz et al. (1992) demonstrated that in rabbits amygdala lesions mildly impair the rate of conditioning. The effect of these amygdala lesions was stronger in a paradigm with a relatively low intensity CS (65 dB), which elicits only submaximal CR acquisition. In line with this effect, stimulation of the rabbit amygdala enhances the amplitude of the nictitating membrane response (Whalen and Kapp, 1991). Interestingly, the role of the amygdala in eyeblink conditioning seems to be more prominent in rats than in rabbits (Mintz and Wang-Ninio, 2001; Neufeld and Mintz, 2001; Lee and Kim, 2004; Blankenship et al., 2005). Both permanent and reversible lesions of the rat amygdala before conditioning robustly impair the acquisition of CRs. During the first five training sessions the impact of these lesions on the level of conditioning is just as detrimental as cerebellar nuclei lesions (Figures 3B1-B3; Lee and Kim, 2004). At later stages, however, the impact of cerebellar lesions is greater. This segregation in two stages may reflect the 'two-process model of conditioning' (Rescorla and Solomon, 1967; Lennartz, 1992; Lee and Kim, 2004), which predicts that nonspecific emotional fear responses, such as increased heart rate, blood pressure and respiration, emerge after only a few CS-US pairings, whereas the development of specific motor CRs requires a greater number of pairings. The initial emotional CRs could facilitate the subsequent acquisition of well-timed motor CRs.

Anatomical and electrophysiological data indicate that the amygdala may indeed facilitate the learning during eyeblink conditioning. The lateral amygdala receives convergent input from both the auditory CS and somatosensory US modalities (for details see "Cued Fear Conditioning" and Figure 1C) (Burton and Craig, 1979; Ledoux et al., 1987; LeDoux et al., 1990; Whalen and Kapp, 1991; Weisz et al., 1992). The lateral amygdala in turn sends its output to the central amygdala, which directly projects to the pontine nuclei that provide the mossy fibers to lobules HVI, HVII, and the paramedian lobule (Mihailoff et al., 1989), thereby 
modulating the effectiveness of the CS signals to the cerebellum. Electrophysiological recordings of the amygdala in rabbits that were aimed at detecting CS and US activities during eyeblink conditioning show that about $60 \%$ of the neurons respond to the CS and more than $70 \%$ to the US. Surprisingly, only a few neurons show enhanced responsiveness to the CS alone after CS-US pairings (Richardson and Thompson, 1984). This finding might partly be explained by the relatively small contribution of the amygdala in rabbit eyeblink conditioning, but possibly also by the phenomenon of 'neuronal competition' in the lateral amygdala during memory formation (see also "Cued Fear Conditioning in Mice and Similarities with Eyeblink Conditioning”).

Conclusively, the cerebellum is essential and sufficient for eyeblink conditioning, but the hippocampus and even more so the amygdala also seem to contribute to the memory formation, suggesting that in normal biological circumstances multiple brain memory systems in fact have to interact to establish the adequate CR.

\section{AUDITORY STARTLE REFLEXES}

A sudden and intense auditory stimulus elicits a fast bodily startle reflex, which includes a rapid eyelid closure and a contraction of facial, neck, and skeletal muscles (Davis et al., 1982; Yeomans and Frankland, 1995; Koch, 1999). This startle reflex has an extremely short latency to onset. Measurements of rats done with ballistic chambers sensing whole-body movements reveal a latency to onset and latency to peak amplitude of about $15 \mathrm{~ms}$ and $30 \mathrm{~ms}$, respectively (Pilz et al., 1988; Koch, 1999). More sensitive are electromyographical (EMG) recordings of face-, neck-, and limb muscles, showing that the startle reflex typically starts in the face and spreads down from there to the neck and body (Caeser et al., 1989). In the EMG trace one can distinguish several peaks within the $30 \mathrm{~ms}$ after stimulus onset (Pilz et al., 1988; Caeser et al., 1989). Both the latency to onset and the peak amplitude of the startle reflex correlate with the stimulus intensity: Increased sound pressure decreases the latency to onset and increases the peak amplitude (Pilz et al., 1987, 1988; Caeser et al., 1989). One component of the facial startle reflex is the eyelid reflex (Koch, 1999). This eyelid startle reflex can also be seen in cat and rat eyeblink conditioning experiments using a relatively mild auditory stimulus (70 dB click or $2.8 \mathrm{kHz} 82 \mathrm{~dB}$ tone, respectively) (Skelton, 1988; Woody and Aou, 1999).

The extremely short latency to onset of eyelid and body startle reflexes indicates that the circuitry underlying these reflexes must involve only a few synaptic connections. As illustrated in Figure 1B the basic auditory startle circuit is formed by only three central neurons, including the cochlear root nuclei, the giant neurons in the caudal pontine reticular nucleus $(\mathrm{PnC})$, and the motoneurons in the brainstem or spinal cord (Davis et al., 1982, 1993; Lingenhohl and Friauf, 1994; Koch, 1999; Fendt et al., 2001). Blockage of glutamate receptors in the PnC prevents both the expression of the head and whole-body startle reflex (Krase et al., 1993). Since the $\mathrm{PnC}$ receives excitatory inputs from multiple afferent systems in the lower brainstem including not only the dorsal and ventral cochlear nucleus, but also the lateral superior olive and ventrolateral tegmental nucleus (connections at the bottom of Figure 1B), it is not surprising that $\mathrm{PnC}$ neu- rons demonstrate, just like the peaks in the EMG trace, multiple peaks in their EPSP activity at particular latencies (Lingenhohl and Friauf, 1994; Koch, 1999). In addition to these simple circuits, direct and indirect projections from the central amygdala to the PnC control the expression of the startle reflex (connections shown at the top of Figure 1B). Increased activity in the amygdala enhances the responsiveness of giant $\mathrm{PnC}$ neurons to auditory stimuli and thereby also the startle behavior (Rosen et al., 1991; Davis et al., 1993) indicating that fear potentiation of the startle reflex is under control of plasticity processes in the amygdala (Davis, 1992).

\section{CUED FEAR CONDITIONING}

During a typical cued fear conditioning experiment a tone (CS) is paired with an aversive foot shock (US). After a few CS-US pairings the previously behaviorally neutral tone elicits a wide range of defensive responses (LeDoux, 2000; Pare et al., 2004). These responses include gross reactions of the skeletal musculature resulting in typical freezing behavior, facial contractions, increased respiration, increased blood pressure and heart rate, and pupillary dilations (Lennartz, 1992). Damage to the lateral amygdala, in particular the dorsal subregion, strongly interferes with both the acquisition and expression of these fear CRs indicating that at least an essential part of the convergence of the CS and US occurs in the lateral amygdala (LeDoux et al., 1990; Campeau and Davis, 1995; Fanselow and LeDoux, 1999). The auditory CS signals are mainly relayed from the cochlear nucleus via the inferior colliculus and medial geniculate body of the thalamus to the lateral amygdala (LeDoux et al., 1990). In addition, there is an extra auditory loop via the auditory cortex (Figure 1C). The electrical US signals from the foot shock also terminate in the lateral amygdala; they are relayed via the spino-thalamic tract and the lateral intralaminar nucleus of the thalamus (Shi and Davis, 1999; LeDoux, 2000). The lateral amygdala exerts its main action on the fear CR via the central amygdala, which projects directly to several brainstem nuclei including the hypothalamus, peri-aqueductal gray matter, bed nucleus of the stria terminalis, and PnC. Each of these structures contributes to a particular aspect of the general fear reaction (Figure 1C) (Killcross et al., 1997; Pitkanen et al., 1997; Pare et al., 2004).

Plasticity in the amygdala during fear conditioning has been extensively described (Quirk et al., 1995; Rogan et al., 1997; Bauer et al., 2001; Blair et al., 2001; Rumpel et al., 2005; Won and Silva, 2008). Neurons in the dorsal part of the lateral amygdala in rats show increased tone-evoked firing rates due to long-term potentiation (LTP) induced by fear conditioning. The latency of the earliest responses of these neurons is about $20 \mathrm{~ms}$ following the tone onset in a fear conditioning trial (Quirk et al., 1995). Neurons in the basolateral and ventral areas of the lateral amygdala also demonstrate clear responses, but at latencies of about 40 and $50 \mathrm{~ms}$, respectively (Muramoto et al., 1993; Quirk et al., 1995). Interestingly, after destruction of the amygdala, fear CRs can be reacquired. This reacquisition only occurs if the animals are trained before the amygdala is lesioned (Kim and Davis, 1993). This finding suggests that extra-amygdalar regions also play a role in memory storage during fear conditioning. One of these regions could in fact be the cerebellum, because lesions of the cerebellar vermis 
severely disrupt fear memory (Supple and Leaton, 1990), and LTP at inhibitory synapses in the cerebellar vermis can be related to associative processes during fear learning (Sacchetti et al., 2005, 2009; Scelfo et al., 2008). Taken together, during cued fear conditioning the amygdala and cerebellum closely seem to interact to establish the fear $\mathrm{CR}$, mediated by indirect anatomical projections between the two structures.

\section{EYEBLINK CONDITIONING IN MICE}

In contrast to detailed neuro-anatomical studies done in cats, rabbits, ferrets, and rats, the fundamental anatomical knowledge underlying eyeblink conditioning in mice is limited up to now. Most work done in mice was aimed to investigate cerebellar molecular mechanisms underlying eyeblink conditioning by using transgenic mice, thereby assuming that in mice the contributions of the cerebellar cortex and cerebellar nuclei to eyeblink conditioning are similar to those of other mammals. Studies on Purkinje cell plasticity processes underlying eyeblink conditioning reported disturbed CR acquisition in mGluR1 mutant mice (Aiba et al., 1994), Purkinje cell degenerative (pcd) mice (Chen et al., 1996), GluR $\delta 2$-deficient mice (Kishimoto et al., 2001b), phospholipase C $\beta 4$ mutant mice (Miyata et al., 2001), Purkinje cell-specific protein kinase C inhibitor overexpressing mice (Koekkoek et al., 2003), and Fmr1 knockout mice (Koekkoek et al., 2005). In line with these findings Purkinje cell-specific mGluR1-rescue mice show normal learning in a delay eyeblink conditioning paradigm (Kishimoto et al., 2002). Mice lacking electrical coupling among their olivary neurons that provide the climbing fibers to the cerebellar cortex show disturbed timing of their CRs. This phenotype might be due to the fact that the balance between LTD and LTP induction in Purkinje cells is disturbed (Koekkoek et al., 2003; Van Der Giessen et al., 2008). First attempts to define the eyeblink controlling regions in the cerebellar cortex in mice indicate that corneal air puff responding Purkinje cells are located at least in the simplex lobule and adjacent parts of lobule HVI (Van Der Giessen et al., 2008), which is in agreement with findings previously obtained from other mammals (see Eyeblink Conditioning). Synaptic processes in the interposed nuclei also seem to be crucial during mouse eyeblink conditioning. First, bilateral infusions of both GABAa receptor agonists and antagonist in the cerebellar nuclei impair acquisition of eyeblink CRs (Sakamoto and Endo, 2008). Second, Wada et al. (2007) reported normal acquisition when granule cell transmission was selectively blocked, suggesting that convergent information at the interposed nuclei is sufficient for the acquisition of eyeblink CRs. Still the CRs in this study are only expressed after removal of the blockage. Thus, different from rabbits (Lavond and Steinmetz, 1989; Perrett et al., 1993; Ohyama et al., 2006), in mice the granule cell network may be required for CR expression. Taken together, results from eyeblink studies done in mutant mice show trends that are similar to those that can be seen in functional anatomical and pharmacological studies done in larger mammals. Yet, if one looks at the rate of conditioning, the topographical characteristics of the eyeblink $\mathrm{CR}$, and the technical approaches, several issues in mice differ from other mammals. Below we will discuss these differences and focus on parallels and similarities with cued fear conditioning in order to conclude with a new model on the relative contribution of the amygdala and the cerebellum in mouse eyeblink conditioning.

\section{RATE OF CONDITIONING}

The average percentage CRs in mice usually saturates asymptotically at 50 to 70 after 5 days of training (Chen et al., 1996; Qiao et al., 1998; Kishimoto et al., 2001a; Miyata et al., 2001; Wada et al., 2007; Sakamoto and Endo, 2008). In addition, reported learning curves in mice show an immense variation. For instance, Vogel et al. (2002) reported an average CR percentage of 70 for the first training session while Lee et al. (2009) reported a percentage of less than 40 even after 7 days of training. Averaged eyeblink conditioning learning curves in rabbits and ferrets, in contrast, appear rather consistent. Usually they begin to exhibit first CRs on the second day of training and attain an average CR percentage of 80 to 100 within 5 days of training (Steinmetz et al., 1987; Welsh and Harvey, 1989; Yeo and Hardiman, 1992; Bracha and Bloedel, 1996; Ivarsson and Svensson, 2000; Ohyama and Mauk, 2001; Villarreal and Steinmetz, 2005). The lower average percentage of CRs in mice might be partly due to the typical experimental design when using mice (i.e. group comparison of eyeblink conditioning rates of knockout mice versus their wild-type littermates) that does not allow exclusion of animals that do not reach a certain criterion such as a minimum CR percentage after a particular training period. The variation in reported learning curves in mice could partly be explained by the use of mice with different backgrounds and ages (Paylor and Crawley, 1997; Kishimoto et al., 2001a; Vogel et al., 2002). However, it probably also reflects multiple inconsistencies in the experimental paradigms including different stimulation and recording methodologies and different exclusion and inclusion criteria for CR identification. Due to these inconsistencies comparisons of results from different studies using mice are difficult to make.

\section{TOPOGRAPHICAL CHARACTERISTICS OF THE CONDITIONED EYEBLINK TRACES IN MICE}

The topographical characteristics of eyeblink responses during conditioning in mice seem to differ from those in other mammals. EMG traces in several studies show that mice respond to the CS with a rapid robust eyelid closure whereby the eyelid remains closed during the rest of the ISI (see for instance EMG traces in Kishimoto et al., 2001b, 2002; Sakamoto and Endo, 2008). These responses have a latency to onset of about $60-80 \mathrm{~ms}$ and a latency to peak amplitude of about $100 \mathrm{~ms}$ (Kishimoto et al., 2001b, 2002; Wada et al., 2007; Sakamoto and Endo, 2008), and thereby stand in marked contrast to those of rabbits and ferrets, which show a gradual closing of the eyelid in the CS-US interval with the peak amplitude perfectly coinciding with the US onset (Perrett et al., 1993; Ivarsson and Svensson, 2000; Aksenov et al., 2004). The rapid eyelid response in mice seems to reflect a motoneuronal burst activity and one might doubt the cerebellar origin of this type of eyelid response. Further, the small startle reflex within $50 \mathrm{~ms}$ after CS onset, which has also been described for cats and rats (Skelton, 1988; Woody and Aou, 1999), seems to be more prominently present in the mouse conditioned eyeblink trace.

When measured with the Magnetic Distance Measurement Technique (MDMT) one can usually distinguish two different peaks between the startle reflex and the UR. These two peaks include a short-latency response (SLR) and a CR (Figure 2A) (Koekkoek et al., 2003, 2005). The SLR was first mentioned in a pioneering mouse eyeblink conditioning study done by Tonegawa's laboratory 
(Aiba et al., 1994) and later confirmed by others (Vogel et al., 2002). In the MDMT signal a typical SLR has a peak amplitude of about $0.4 \mathrm{~mm}$, a latency to onset of 50-70 ms, a latency to peak amplitude of $115 \mathrm{~ms}$, and a duration that extends over the ISI (Figures 2A,E). Both latency to onset and latency to peak amplitude are relatively

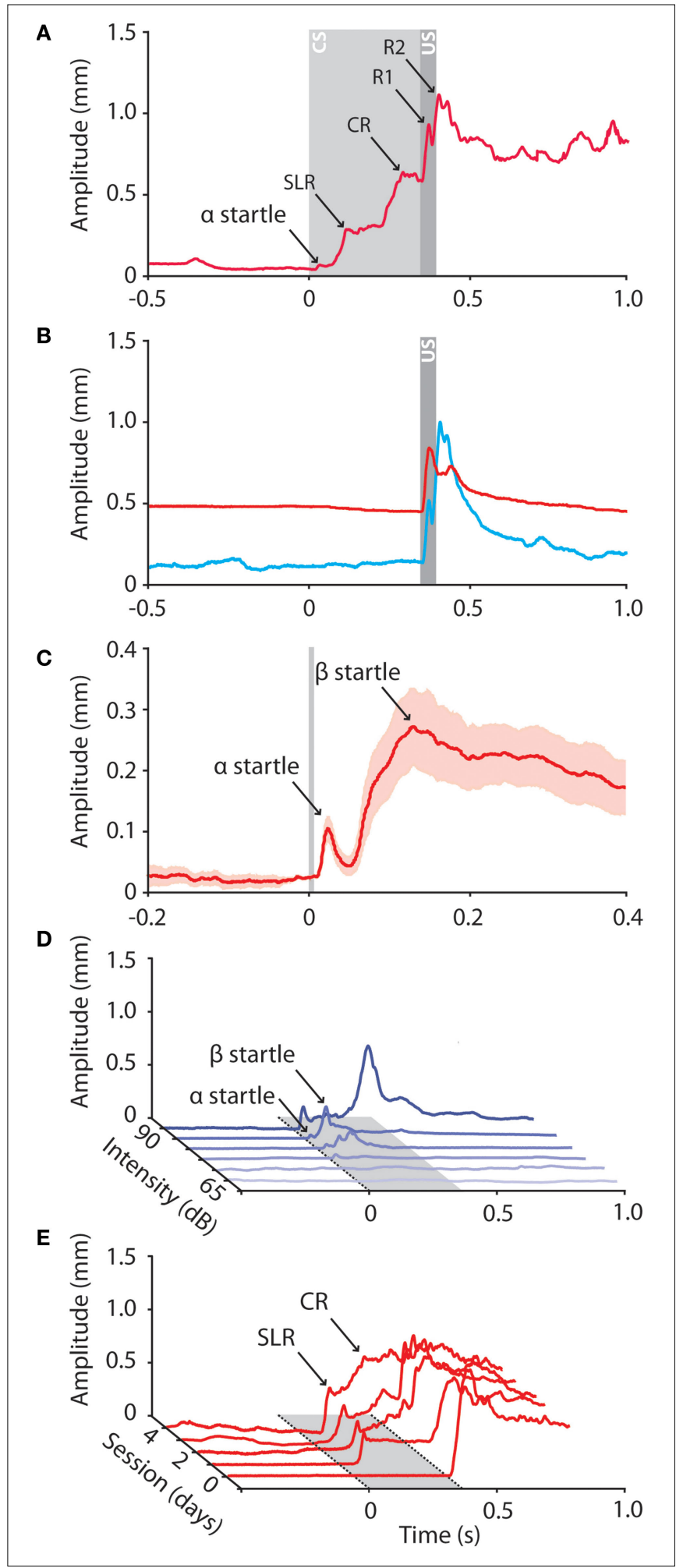

fixed, i.e. they are independent of the ISI and they do not shift in the eyeblink trace during consecutive training sessions. The shape of these SLRs is similar to the rapid eyelid responses measured with EMG as described above. In contrast to startle reflexes, SLRs increase in number over especially the first training sessions and they occur relatively infrequently in unpaired trials when a behaviorally neutral tone is used (Aiba et al., 1994; Vogel et al., 2002). This suggests that SLRs are learned and associative. Vogel et al. (2002) reported that only a few CS-US pairings can already establish SLRs, a finding that is also confirmed by our lab. Due to their magnitude and duration SLRs might lead to misinterpretations of the real cerebellar CR. The characteristics of SLRs also differ from those of CRs, which occur later in the ISI and which require more paired trials to become clearly apparent. Moreover, during the consecutive training sessions also in mice the CR peak amplitude usually increases and shifts towards US onset (Aiba et al., 1994; Miyata et al., 2001; Sakamoto and Endo, 2008). Thus, SLRs appear to be rather early, aspecific, learned eyelid responses, whereas CRs occur, as expected, at the time of the US. The fact that SLRs require only a few CS-US pairings raises the question whether they are, like conditioned fear responses, also originating from the amygdala.

Further evidence for the hypothesis that SLRs in mice have an extracerebellar origin comes from studies demonstrating that, in contrast to other mammals, lesions of the interposed nuclei in mice do not fully abolish previously learned eyelid responses to the CS (Koekkoek et al., 2003, 2005; Sakamoto and Endo, 2008). For several reasons it is unlikely that the remaining eyelid responses in these studies were the result of incompleteness of the lesions. First, the interposed nuclei lesions made by Koekkoek et al. (2003, 2005) were bilateral, and silver staining of the efferent fibers from the nuclei showed that the lesions resulted in degeneration of fibers in all the relevant output tracts (Figures 3A1,A2). Second, the lesions did not affect only the percentage of CRs, but they also affected the overall shape of the eyelid response in that well-timed CRs disappeared, while the remaining responses had the typical shape of SLRs as described above (Figure 3A3). Third, compara-

FIGURE 2 | Raw data traces obtained from mice during eyeblink conditioning and auditory startle reflexes. (A) Different peaks can be distinguished in the conditioned eyeblink trace, including a small startle peak, a short-latency response (SLR), a conditioned response (CR), and two or more unconditioned response peaks (R1 and R2). In all panels: tone onset at $t=0$; puff onset at $t=350$; CS duration $380 \mathrm{~ms}$; US duration $30 \mathrm{~ms}$; ISI $350 \mathrm{~ms}$; at amplitude $=0 \mathrm{~mm}$ the eyelid is maximum opened, at $1 \mathrm{~mm}$ the eyelid is fully closed. (B) Raw data traces of a reflexive eyeblink response of a mouse when awake behaving (blue) and during 'quiet wakefulness' (red). When behaving the eyelid is fully open and the oscillatory properties of the eyelid motor system are clearly visible in the eyeblink response. During quiet wakefulness the mouse sits very quiet, the eyelid is half closed, the baseline is completely flat, and there is a virtual absence of the normal oscillations of the eyelid response. (C) Mean ( \pm SEM) of 20 raw data traces of eyelid startle reflexes in response to a loud auditory tone $(90 \mathrm{~dB}, 10 \mathrm{kHz})$. Note that, when presented such a loud tone, two startle peaks ( $\alpha$ and $\beta$ ) can be distinguished in the raw data traces. (D) The amplitude of the auditory startle reflex correlates with the intensity of the auditory stimulus. First small $\alpha$ responses emerge, whereas $\beta$ responses appear when the tone intensity is increased. (E) Example raw data traces of a mouse over the consecutive training sessions. During habituation session (T-0) the behaviorally neutral CS does not elicit eyelid responses. During the first paired training sessions SLRs emerge whereas prolonged training results in well-timed CRs. 


\section{Interposed nuclei lesions}
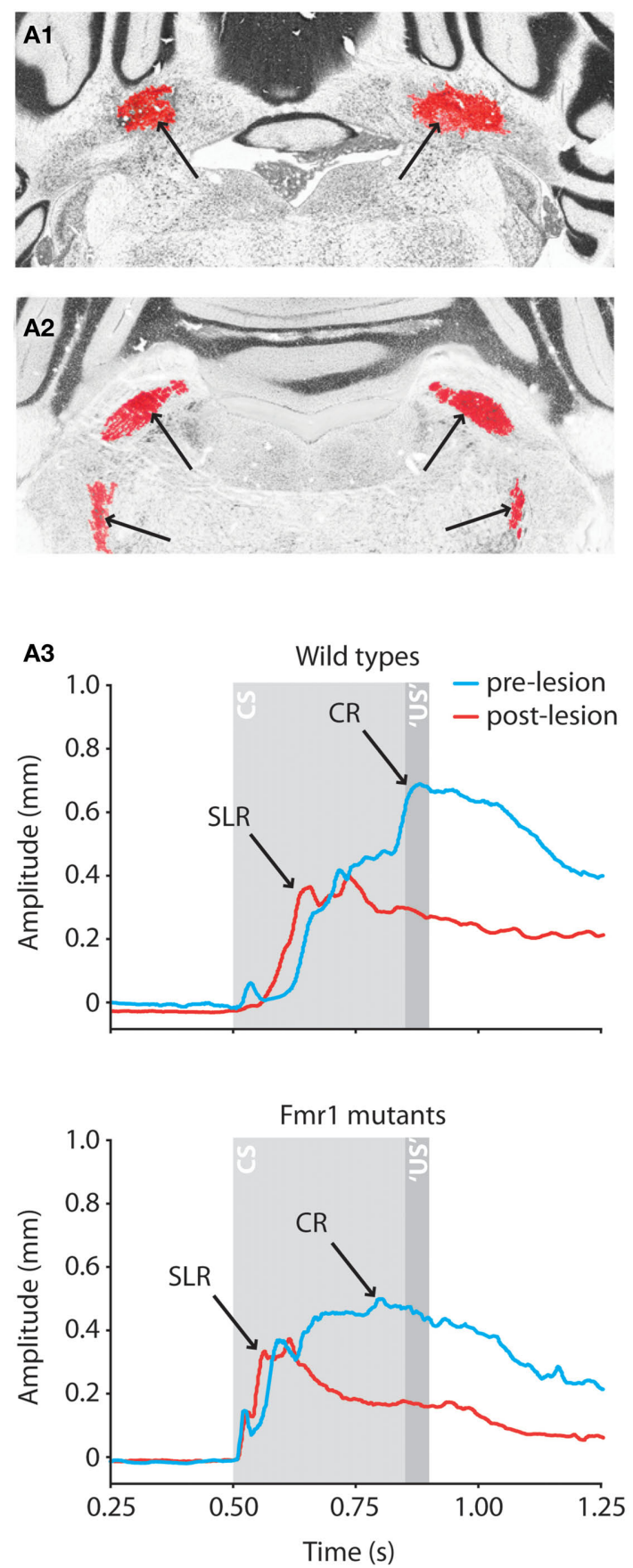

FIGURE 3 | Effects of anterior interposed nucleus lesions in mice and amygdala lesions in rats on eyeblink conditioning. (A1) Example of bilateral lesion (arrows) of anterior interposed nucleus in Nissl-stained section of Fmr1 mutant. (A2) Example of degenerated axonal fibers (silver staining is indicated by arrows) in the superior cerebellar peduncle and ipsilateral descending tracts. (A3) Eyeblink traces showing the average amplitudes of the CRs in wild-type and Fmr1 mutants before (blue) and after (red) the lesions. In both mutants and wild-types lesions of the anterior interposed nucleus abolish well-timed cerebellar CRs, whereas startle reflexes and SLRs are still present in the eyeblink trace. Reproduced with permission from Koekkoek et al. (2005).

\section{Amygdala lesions}

B1

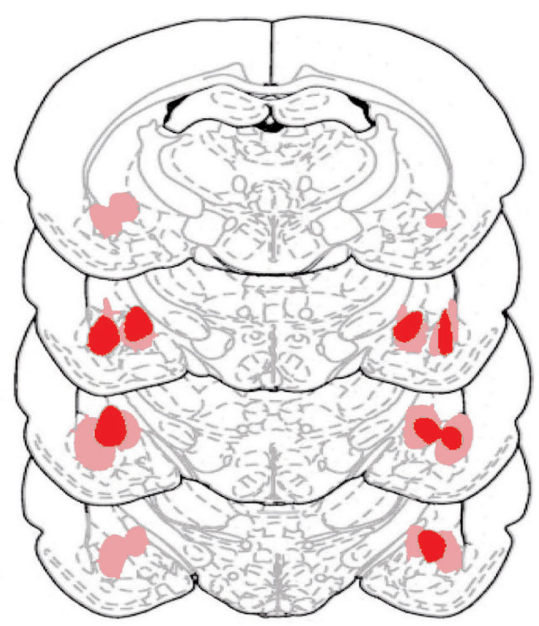

B2

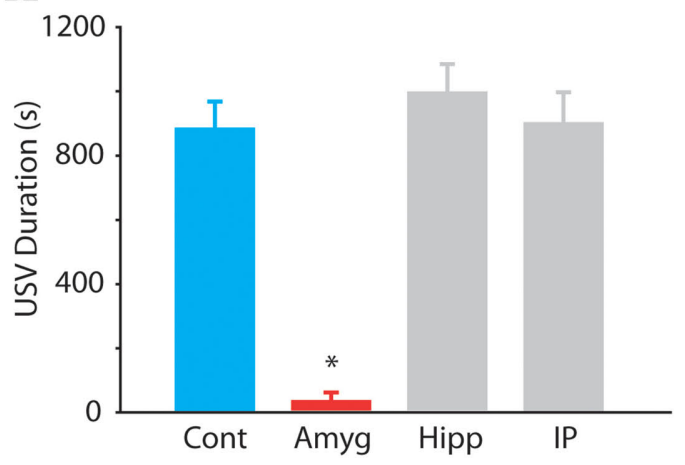

B3

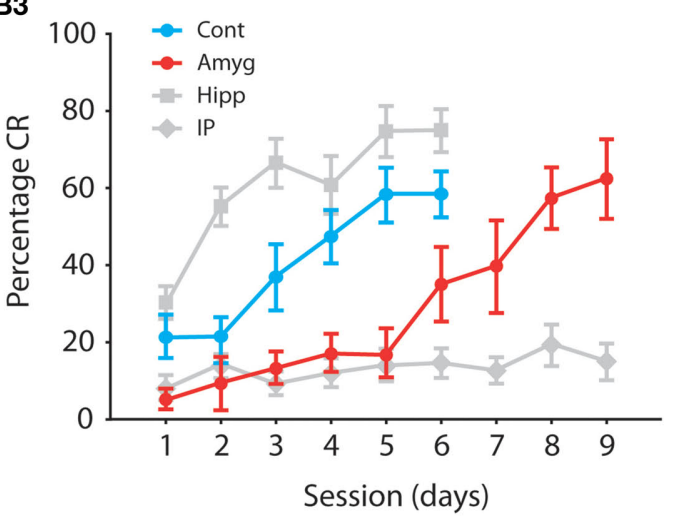

(B1) Histological reconstructions of amygdala lesion sites in rats. Numbers indicate distance in millimeters posterior to Bregma. (B2) Mean ultrasonic vocalization (USV) during day 6 of the training sessions. The USV duration is a valid model of anxiety in rats (Sanchez, 2003), and a reduced USV duration behaviorally confirms the lesions of the amygdala. (B3) Mean percentage of CR $( \pm$ SEM) during daily training sessions from control $(n=9)$, interposed nuclei lesioned ( $n=9)$, amygdala lesioned ( $n=9)$, and hippocampus lesioned $(n=10)$ rats. Lesions of the amygdala robustly slowed down the acquisition of eyeblink CRs indicating that the amygdala modulates the eyeblink conditioning process. Reproduced with permission from Lee and Kim (2004). 
ble lesions made by Sakamoto and Endo (2008) with a reversible approach (i.e. muscimol and picrotoxin infusions) also could not completely abolish previously learned eyelid CRs. They even found an increase of the responses for the training sessions after infusions. In contrast to Koekkoek et al. (2003, 2005), Sakamoto and Endo did not report any change in latency to onset or latency to peak amplitude of the residual responses.

In cats, rabbits, and ferrets, one can also observe different peaks in their conditioned eyeblink trace. Ivarsson and Svensson (2000) reported two distinctive components in the conditioned eyeblink trace of ferrets and rabbits. However, mean latency to onset of the first peak (CR1) is about $150 \mathrm{~ms}$, which is not compatible with the short latency to onset of SLRs in mice. Further, as mentioned above, SLR with similar shapes have also been described in rabbits after cerebellar cortex lesions. If sufficiently large, these lesions can induce responses with a latency to onset of about 60-80 ms and a latency to peak amplitude of 115-130 ms (Perrett et al., 1993), which are in line with the SLRs in mice (Koekkoek et al., 2003, 2005). In cats, one can distinguish at least four different peaks in the eyeblink trace (Woody and Aou, 1999). When we compare the latencies of these four peaks two of them, $\alpha_{2}$ and early $\beta$ responses, seem to resemble the latencies of SLRs in mice. Both of these responses can also be observed occasionally before training, but their occurrence frequency increases during eyeblink conditioning, suggesting that they have both associative and non-associative properties.

Conclusively, mice show at least two peaks in their conditioned eyeblink traces: an SLR and a CR and these peaks may well have their counterparts in larger mammals. The SLRs form a concern for mouse eyeblink conditioning, because they might lead, due to their magnitude and duration, to misinterpretations of cerebellar CRs. Since each response has different characteristics of the association process, they may originate, at least in part, from different sources.

\section{TECHNICAL CONSIDERATIONS}

The data described above show that both qualitatively and quantitatively several features of the conditioned eyeblink behavior in mice differ from those in other mammals. Below we will consider the impact of the various technical approaches on the outcome of conditioning in mice. Apart from the impact of the precise type of CS, which will be discussed in "Auditory Startle Reflexes in Mice and the Optimal CS for Eyeblink Conditioning", the relevant differences in these approaches include the used US intensities, the specific methods for recording the eyeblink responses, and the control of the level of alertness.

\section{US intensities for eliciting CRs in mice}

In order to evoke sufficient CRs in mice the US usually is provided at a high intensity level. Whereas a relatively mild corneal air puff is enough to obtain a significant amount of CRs in rabbits (Welsh and Harvey, 1989), in mice (but also in rats) a comparably mild US induces a low level of conditioning (Skelton, 1988; Aiba et al., 1994). Therefore, most conditioning paradigms in mice use a strong aversive US, the intensity of which is often increased over the consecutive training sessions. Such a US does not only elicit a robust eyeblink, but often also a rapid head jerk away from the site of stimulation (Chen et al., 1996; Kishimoto et al., 2002; Sakamoto and Endo, 2008; Lee et al., 2009). This approach may make it hard to rely on EMG for recording eyeblink responses in mice, because it will be difficult to distinguish the actual movements of the eyelid from those of other surrounding facial muscles (see also below). Moreover, especially in mice such strong aversive stimuli form a fearful trigger, which can be expected to evoke various defensive behavioral responses involving activities in multiple brain regions. Thus, the requirements for an appropriate US in mice present challenges both for the technical recording methodology and for the interpretation of the regional brain activities involved in eliciting the CRs.

\section{Recording technology for eyeblink responses}

The advent in mouse transgenics has triggered innovative modifications of the physiological recording technologies that were originally designed for larger mammals. For example, EMG, which is a feasible method for measuring eyeblink responses in rabbits (Gormezano et al., 1962; Welsh, 1992; Yeo and Hardiman, 1992), turned out to be too indirect and too sensitive to record selectively eyelid movements in mice (Koekkoek et al., 2002; Vogel et al., 2002). To avoid picking up false positive signals from other facial muscles Koekkoek and colleagues developed MDMT. This technology takes advantage of magnet-sensitive chips and allows direct and precise detection of the actual eyelid movements at a high spatiotemporal resolution, which can be used for quantifying the characteristics of eyeblink responses in mice (Koekkoek et al., 2002).

\section{Controlling the level of alertness}

One explanation for the lower percentage of CRs in mice compared to other mammals might be the relatively high occurrence of periods of 'quiet wakefulness' during the eyeblink conditioning experiment. The state of quiet wakefulness is characterized by the mouse sitting quietly with its eyes half closed, which does not reflect freezing behavior due to anxiety. In the MDMT eyeblink trace quiet wakefulness is represented by a flat and elevated baseline, which, as a consequence, results in a reduced UR amplitude. In addition, there is a virtual absence of the oscillations $(\approx 25 \mathrm{~Hz})$ that are prominently present in the alert state during both the CRs and the URs (Figure 2B) (Trigo et al., 1999; Koekkoek et al., 2002; Delgado-Garcia and Gruart, 2006). During the state of quiet wakefulness even a well-conditioned mouse will not demonstrate CRs. However, the CRs reappear when the animal 'wakes up'. The occurrence of those periods of quiet wakefulness and the tools used to avoid them or to awaken the mouse (e.g. a sudden loud noise) can strongly influence the outcome of the learning process. Interestingly, different internal brain states may well depend upon changes in oscillatory electrical brain activity (Poulet and Petersen, 2008). During periods of quiet wakefulness mice show synchronous, slow large-amplitude oscillations $(1-5 \mathrm{~Hz})$ in the electroencephalogram (EEG) as well as in the single unit recordings of their layer $2 / 3$ pyramidal cells, whereas during a high level of alertness faster low-amplitude oscillations are replacing the slow oscillations. This internal brain state forms a key determinant in attention, expectation, sensorimotor coordination and learning (Gilbert and Sigman, 2007). Probably, the observed reduced oscillations in the eyelid movement in mice during quiet wakefulness reflect the eyelid component of this general internal brain state. Because the state of alertness will 
have a great influence on the rate of eyeblink conditioning in mice, one might consider to deliver mild auditory startle pulses based upon the oscillations in the MDMT signal.

\section{AUDITORY STARTLE REFLEXES IN MICE AND THE OPTIMAL CS FOR EYEBLINK CONDITIONING}

Using a relatively mild auditory tone $(10 \mathrm{kHz}, 70 \mathrm{~dB})$ the auditory startle reflex in mice is represented in the MDMT eyeblink trace by a single peak with an amplitude of ca $0.1 \mathrm{~mm}$, a latency to onset of about $15 \mathrm{~ms}$, and a latency to peak amplitude of $25 \mathrm{~ms}$ (Figures 2A,C). We call this peak, in line with this component in cats, the $\alpha$-startle peak (Woody and Aou, 1999). Our values in mice correspond to those obtained from facial and head EMG recordings in rats at similar sound intensities (Caeser et al., 1989). However, in mice we can frequently observe additional and more complex eyelid responses ( $\beta$-startle peaks) with a much longer latency and a bigger amplitude (Figure 2C). We assume that the $\alpha$-startle peak in mice, as in larger mammals, is formed by the three synapse circuit including the cochlear complex, $\mathrm{PnC}$, and facial nucleus, while the $\beta$-startle reflex is mediated by the longer loop superimposed upon the PnC and cochlear complex (Figure 1B) (Fendt et al., 1996; Koch, 1999). Interestingly, the $\beta$-startle reflex in mice resembles the topographical characteristics of their associative SLRs during eyeblink conditioning, suggesting that the underlying neurocircuitry is similar (compare traces in Figures 2A,C).

In general $\alpha$ responses in mice emerge at lower sound intensities than $\beta$ responses, but the latency to onset, the amplitude and the duration of both the $\alpha$ and $\beta$ eyelid startle reflexes are, similar to those of the whole-body startle reflex, influenced by the intensity of the tone (Figure 2D). The threshold to elicit startle reflexes differs among mice of different backgrounds and age. For example, at $8 \mathrm{kHz}, 129 \mathrm{P} 3 / \mathrm{J}$ and CBA/CaJ mice (male, 15-72 weeks) have a hearing threshold of $70 \mathrm{~dB}$ and $20 \mathrm{~dB}$, respectively (JAX ${ }^{\circledR}$ Mice). In C57Bl/6 mice (12-20 weeks) the threshold to elicit $\beta$-startle reflexes is usually around $75 \mathrm{~dB}$ at $10 \mathrm{kHz}$, but some animals display them already at levels less than $70 \mathrm{~dB}$ (Figure 2D). In addition, the stimulus thresholds to elicit $\alpha$ and $\beta$ startle reflexes in mice show relatively big fluctuations over time in individual animals similar to those described for rats (Pilz et al., 1988). Moreover, in mice auditory stimuli just above hearing threshold already can elicit startle reflexes, indicating that the bandwith between behaviorally neutral and non-neutral auditory stimuli is very narrow. For eyeblink conditioning, in which the auditory stimulus initially serves as a behaviorally neutral CS, this narrow bandwith forms a serious concern. This problem does not pertain so much to the $\alpha$ startle reflexes, which usually diminish over the training sessions (Koekkoek et al., 2005) and can be easily distinguished from CRs, but it holds particularly true for the $\beta$ startle reflexes, which are often topographically indistinguishable from associative SLRs and sometimes even resemble CRs. The occurrence of $\beta$-startle reflexes cq non-associative SLRs in mice may be influenced by the frequency of the auditory CS, but this topic is still subject to debate. Some studies say that they can be reduced by low frequency stimulation at $1 \mathrm{kHz}$ (Lee et al., 2009), but the vast majority of peak latencies of the CRs in these studies still occurs between $85 \mathrm{~ms}$ and $140 \mathrm{~ms}$, which corresponds well to the timing of SLRs. On the contrary, others indicate that low frequency tones at $2 \mathrm{kHz}$ can elicit a large number of startle and non-associative freezing responses at the latency of SLRs (Smith et al., 2007). In our hands a tone frequency at 5 or $10 \mathrm{kHz}$ with a rise/fall time of $25 \mathrm{~ms}$ and a $68 \mathrm{~dB}$ background white-noise is the optimal CS, which elicits minimal startle and non-associative blink reflexes, and supports optimal conditioning. The sound pressure level of a neutral CS differs among mice. Therefore, it is crucial to make a behavioral audiogram for each individual mouse during habituation sessions before the paired training sessions start so as to identify its behaviorally neutral $\mathrm{dB}$. However, despite all efforts to minimize and control both startle reflexes and non-associative SLRs, both do remain present during eyeblink conditioning experiments in mice, indicating that a behaviorally neutral CS is almost elusive.

\section{CUED FEAR CONDITIONING IN MICE AND SIMILARITIES WITH EYEBLINK CONDITIONING}

The advent of mouse transgenics has also been advantageous for elucidating some of the mechanisms in the amygdala that underlie cued fear conditioning. For example, LTP induction at thalamic inputs to the lateral amygdala projection neurons and the glutamatergic synapses in the basal amygdala is absent in GluR1, but normal in GluR3 mutant mice (Humeau et al., 2007). As a consequence GluR1 mutant mice do not display conditioned freezing in response to an auditory CS, whereas GluR3 knockouts on the other hand show normal learning in a cued fear conditioning paradigm (Humeau et al., 2007). Mice that express $\alpha$ calcium-calmodulindependent kinase II ( $\alpha$ CaMKII) that cannot undergo inhibitory phosphorylation have lower thresholds for LTP and a high level of freezing before and after tone onset in a cued conditioning paradigm (Elgersma et al., 2002). In addition, mouse transgenic studies have allowed us to examine 'neuronal competition' in the lateral amygdala during memory formation (Han et al., 2007). Although $70 \%$ of the lateral amygdala neurons receive convergent input of the foot shock US and tone CS, only 25\% of them exhibit cued fear conditioning induced plasticity. This relatively low percentage could possibly explain why earlier recordings in the amygdala of rabbits that were aimed at detecting CS and US activities during eyeblink conditioning showed only a few amygdala neurons with enhanced responsiveness to the CS after CS-US pairings (Richardson and Thompson, 1984). As mentioned above, the cerebellum is also involved in cued fear conditioning. The ionotropic glutamate receptor delta2 subunit (GluR $\delta 2$ ) is specifically expressed at the postsynaptic site of the parallel fiber to Purkinje cell synapse (Araki et al., 1993; Yuzaki, 2003). Mice that lack this GluR $\delta 2$ show impaired acquisition in a delay eyeblink conditioning paradigm (Kishimoto et al., 2001b). However, these mice also have short- and long-term memory impairments in a cued fear conditioning paradigm (Sacchetti et al., 2004). This finding suggests that the cerebellum also participates in the neural circuitry subserving emotional fear responses.

Interestingly, when aversive US intensities are used, as is typical in eyeblink experiments with mice, the main difference between fear and non-fear (i.e. eyeblink) conditioning may well disappear. Too rigid implementation of theoretical categorizations of fear versus non-fear conditioning can thus easily lead to an overly restrictive consideration of the underlying neural processes. 


\section{THE ACDC MODEL: AN INTEGRATED HYPOTHESIS OF EYEBLINK CONDITIONING IN MICE}

As explained above, the magnitude and duration of the SLRs in mice might lead to misinterpretation of the origin and the percentage of CRs. We hypothesize that the associative properties of SLRs have an extracerebellar origin, most likely the amygdala, which is known to be central in the control of conditioned fear responses. It has been shown that the relative contribution of the amygdala to the eyeblink conditioning process differs among animals. Whereas its role seems to be minimal in rabbits, in rats the amygdala plays an important role in modulating the eyeblink conditioning process by enhancing the effectiveness of the CS and the arousal of the animal. The amygdala is in a good position to modulate the CS input to the cerebellum, because it projects directly to the pontine nuclei neurons that provide the mossy fibers (Figure 4) (Mihailoff et al., 1989). In mice the role of the amygdala during eyeblink conditioning has not been investigated yet. As in rats, the amygdala might be important for enhancing the effectiveness of the CS and the arousal of the animal. Further, we hypothesize that especially in mice the amygdalar contribution is directly resembled by an SLR in the eyeblink trace.

Thus, the Amygdala-Cerebellum-Dynamic-Conditioning Model predicts that the amygdala contributes to the early associative SLR that occurs rather rapidly in the beginning of training, while the cerebellum is mainly involved in controlling the later, well-timed CR that coincides with the onset of the US and that slowly emerges as the training proceeds (Figure 2E). Both the amygdala and the cerebellum can contribute to the various associative components when the following three conditions are met: (i) both CS and US inputs converge upon the same neurons; (ii) these neurons serve as an output to exert motor control; and (iii) learning induced plasticity creates an adequate novel output (i.e. the CR). Both systems meet these conditions. Auditory CS

FIGURE 4 |The Amygdala-Cerebellum-Dynamic-Conditioning Model. An integrated model to explain the different phases in the mouse eyeblink conditioning learning process and the different peaks in the individual eyeblink traces. The colors in the model eyeblink trace represent the anatomical afferents to the FN or PnC. During eyeblink conditioning the tone (CS) and corneal air puff (US) converge at least in the amygdala and cerebellum. They are relayed to the LA from thalamic and cortical regions of the auditory (green) and somatosensory (purple) systems. Pontocerebellar (green) and olivocerebellar (blue) systems mediate the convergence of CS and US on Purkinje cells in the cerebellar cortex and to a lesser extent on the IN neurons. Amygdala and cerebellum control the $\mathrm{FN}$ activity via $\mathrm{PnC}$ (red) and $\mathrm{RN}$ (gray), respectively. During the first learning phase in eyeblink conditioning very efficient plasticity in the LA results in mild conditioned fear responses, including rapid facial responses such as an eyelid closure. This is represented in the eyeblink trace by an SLR (red). A few CS-US pairings are enough to obtain clear SLRs in mice. Prolonged training will induce cerebellar learning, which behaviorally is represented by a perfectly timed eyelid closure (gray). In addition, direct projections from the amygdala to the PN might contribute directly to the CS input of the cerebellum. Thus, the ACDC model assumes that neuronal mechanism in different brain regions contribute to the establishment of an adequate $\mathrm{CR}$. AC, Auditory cortex; $\mathrm{CE}$, Central amygdala; $\mathrm{CN}$, Cochlear nucleus; CrN, Cochlear root nucleus; CS, Conditioned stimulus; FN, Facial nucleus; GC, Granule cell; IN, Interposed nuclei; IO, Inferior olive; LA, Lateral amygdala; MGB, Medial geniculate body of the thalamus; MN, Motor neurons; PC, Purkinje cell; PIN, Posterior intralaminar nucleus of the thalamus; PN, Pontine nuclei; PnC, Caudal pontine reticular nucleus; RN, Red nucleus; SC, Somatosensory cortex; TrN, Trigeminal nerve nucleus; US, Unconditioned stimulus. and somatosensory US inputs converge in the lateral amygdala. While the cochlear nucleus relays the auditory CS to the medial geniculate body of the thalamus and from there to the lateral amygdala, the trigeminal nucleus mediates the peri-orbital US signals via the posterior intralaminar nucleus of the thalamus to the lateral amygdala (Figure 4) (Burton and Craig, 1979; Ledoux et al., 1987; Whalen and Kapp, 1991). Presumably because of convergent activities during fear conditioning, LTP can be induced in neurons of the lateral amygdala, and as a consequence the auditory responses of these neurons can be enhanced (Rumpel et al., 2005; Humeau et al., 2007). Since these neuronal responses occur at latencies between $20 \mathrm{~ms}$ and $50 \mathrm{~ms}$ (Quirk et al., 1995), and since the lateral amygdala sends it output via the central amygdala and $\mathrm{PnC}$ to the facial nucleus, these neuronal latencies are in line with the latency to onset (about 50-70 ms) of the eyelid SLRs in mice during eyeblink conditioning. For the cerebellum, it is clear that the auditory CS is mediated by the cochlear and pontine neurons to the granule cells in the cerebellar cortex, and that their parallel fibers converge on Purkinje cells with the US

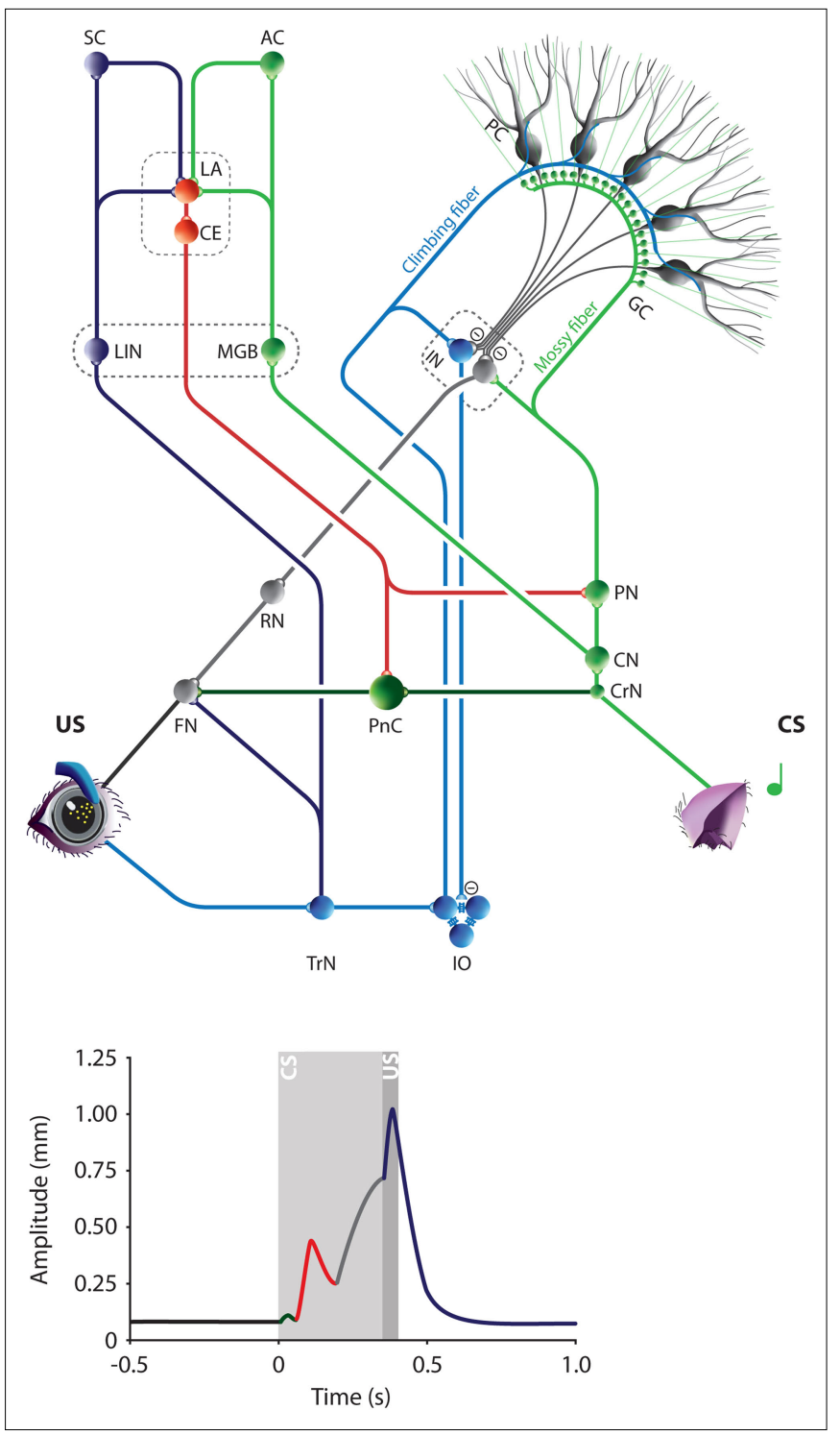


signals that are mediated by the climbing fiber system (Yeo et al., 1985; Steinmetz et al., 1989). The Purkinje cells in turn can well provide the output that is required to modulate the interposed nuclei neurons that control the red nucleus and thereby the facial and oculomotor nucleus motor neurons (Morcuende et al., 2002; Jirenhed et al., 2007). It is still under debate which cellular mechanisms are induced during convergent, associative eyeblink activity in the cerebellum (Kishimoto et al., 2001b; Koekkoek et al., 2003; Welsh et al., 2005). Both the simple spike and complex spike activity of Purkinje cells are reduced during the acquisition process (Jirenhed et al., 2007). Thus, during eyeblink conditioning using an auditory CS and a peri-orbital US convergence of stimuli does occur both in the lateral amygdala and in the cerebellum, these systems both have a central output that exerts motor control of the eyelid muscles, and learning induced plasticity takes place in both systems. In addition, the amygdala and cerebellum may interact with each other. Thus, the ACDC model can explain sev-

\section{REFERENCES}

Aiba, A., Kano, M., Chen, C., Stanton, M. E., Fox, G. D., Herrup, K., Zwingman, T. A., and Tonegawa, S. (1994). Deficient cerebellar long-term depression and impaired motor learning in mGluR1 mutant mice. Cell 79, 377-388.

Aksenov, D., Serdyukova, N., Irwin, K., and Bracha, V. (2004). GABA neurotransmission in the cerebellar interposed nuclei: involvement in classically conditioned eyeblinks and neuronal activity. J. Neurophysiol. 91, 719-727.

Albus, J. S. (1971). A theory of cerebellar function. Math. Biosci. 10, 25-61.

Aou, S., Woody, C. D., and Birt, D. (1992). Changes in the activity of units of the cat motor cortex with rapid conditioning and extinction of a compound eye blink movement. J. Neurosci. 12, 549-559.

Araki, K., Meguro, H., Kushiya, E., Takayama, C., Inoue, Y., and Mishina, M. (1993). Selective expression of the glutamate receptor channel delta 2 subunit in cerebellar Purkinje cells. Biochem. Biophys. Res. Commun. 197, 1267-1276.

Barski, J. J., Dethleffsen, K., and Meyer, M. (2000). Cre recombinase expression in cerebellar Purkinje cells. Genesis 28, 93-98.

Bauer, E. P., LeDoux, J. E., and Nader, K. (2001). Fear conditioning and LTP in the lateral amygdala are sensitive to the same stimulus contingencies. Nat. Neurosci. 4, 687-688.

Berger, T.W., and Thompson, R. F. (1978). Neuronal plasticity in the limbic system during classical conditioning of the rabbit nictitating membrane response. I. The hippocampus. Brain Res. 145, 323-346.

Blair, H. T., Schafe, G. E., Bauer, E. P., Rodrigues, S. M., and LeDoux, J. E. projections to the two sides of the

eral unique features of eyeblink conditioning in mice, like the occurrence of the typical SLRs during normal acquisition training, which cannot be abolished by lesions of the cerebellar nuclei. Further validation of the ACDC model awaits. It will be interesting to find out if SLRs and CRs can be produced independently in mice. In principle, one should be able to bypass the contribution of the amygdala proper by electrically stimulating the pontine nuclei, thereby removing the SLRs that occur with eyeblink conditioning using auditory stimulation. This type of experiment, together with those in which the mouse amygdala is lesioned, should show whether the ACDC model is correct.

\section{ACKNOWLEDGMENTS}

This work was supported by the Dutch Organisation for Medical Sciences (ZON-MW), Life Sciences (NWO-ALW), Senter (NeuroBsik), Prinses Beatrix Fonds, and the European Community (EEC; SENSOPAC).

cerebellum. Brain Res. Brain Res. Rev. 49, 280-294.

(2001). Synaptic plasticity in the lateral amygdala: a cellular hypothesis of fear conditioning. Learn. Mem. 8, 229-242.

Blankenship, M. R., Huckfeldt, R., Steinmetz, J. J., and Steinmetz, J. E. (2005). The effects of amygdala lesions on hippocampal activity and classical eyeblink conditioning in rats. Brain Res. 1035, 120-130.

Bracha, V., and BIoedel, J. R. (1996). The multiple-pathway model of circuits subserving the classical conditioning of withdrawal reflexes. In Acquisition of Motor Behavior in Vertebrates, J. R. Bloedel, T. Ebner and S. Wise, eds (Cambridge, MA, MIT Press), pp. 175-204.

Burton, H., and Craig, A. D. Jr. (1979). Distribution of trigeminothalamic projection cells in cat and monkey. Brain Res. 161, 515-521.

Caeser, M., Ostwald, J., and Pilz, P. K. (1989). Startle responses measured in muscles innervated by facial and trigeminal nerves show common modulation. Behav. Neurosci. 103, 1075-1081.

Campeau, S., and Davis, M. (1995). Involvement of subcortical and cortical afferents to the lateral nucleus of the amygdala in fear conditioning measured with fear-potentiated startle in rats trained concurrently with auditory and visual conditioned stimuli. J. Neurosci. 15, 2312-2327.

Chen, L., Bao, S., Lockard, J. M., Kim, J. K., and Thompson, R. F. (1996). Impaired classical eyeblink conditioning in cerebellar-lesioned and Purkinje cell degeneration (pcd) mutant mice. $J$. Neurosci. 16, 2829-2838.

Cicirata, F., Zappala, A., Serapide, M. F., Parenti, R., Panto, M. R., and Paz, C. (2005). Different pontine
Davis, M. (1992). The role of the amygdala in fear and anxiety. Annu. Rev. Neurosci. 15, 353-375.

Davis, M., Falls, W. A., Campeau, S., and Kim, M. (1993). Fear-potentiated startle: a neural and pharmacological analysis. Behav. Brain Res. 58, 175-198.

Davis, M., Gendelman, D. S., Tischler, M. D., and Gendelman, P. M. (1982). A primary acoustic startle circuit: lesion and stimulation studies. J. Neurosci. 2, 791-805. A. (2002). The role of interpositus nucleus in eyelid conditioned responses. Cerebellum 1, 289-308.

Delgadoz-Garcia, J. M., and Gruart, A. (2005). Firing activities of identified posterior interpositus nucleus neurons during associative learning in behaving cats. Brain Res. Brain Res. Rev. 49, 367-376.

Delgado-Garcia, J. M., and Gruart, A. (2006). Building new motor responses: eyelid conditioning revisited. Trends Neurosci. 29, 330-338. (1983). Do pontocerebellar fibers send collaterals to the cerebellar nuclei? Brain Res. 259, 127-131.

Elgersma, Y., Fedorov, N. B., Ikonen, S., Choi, E. S., Elgersma, M., Carvalho, O. M., Giese, K. P., and Silva, A. J. (2002). Inhibitory autophosphorylation of CaMKII controls PSD association, plasticity, and learning. Neuron 36, 493-505.

Fanselow, M.S., and LeDoux, J. E. (1999). Why we think plasticity underlying Pavlovian fear conditioning occurs in the basolateral amygdala. Neuron 23, 229-232.

Fendt, M., Koch, M., and Schnitzler, H. U. (1996). Somatostatin in the pontine
Delgado-Garcia, J. M., and Gruart,

Dietrichs, E., Bjaalie, J. G., and Brodal, P. reticular formation modulates fear potentiation of the acoustic startle response: an anatomical, electrophysiological, and behavioral study. J. Neurosci. 16, 3097-3103.

Fendt, M., Li, L., and Yeomans, J. S. (2001). Brain stem circuits mediating prepulse inhibition of the startle reflex.Psychopharmacology (Berl.) 156, 216-224.

Freeman, J. H. Jr., and Rabinak, C. A. (2004). Eyeblink conditioning in rats using pontine stimulation as a conditioned stimulus. Integr. Physiol. Behav. Sci. 39, 180-191.

Gilbert, C. D., and Sigman, M. (2007). Brain states: top-down influences in sensory processing. Neuron 54, 677-696.

Gormezano, I., Schneiderman, N., Deaux, E., and Fuentes, I. (1962). Nictitating membrane: classical conditioning and extinction in the albino rabbit. Science 138, 33-34.

Gould, T. J., Sears, L. L., and Steinmetz, J.E. (1993). Possible CS and US pathways for rabbit classical eyelid conditioning: electrophysiological evidence for projections from the pontine nuclei and inferior olive to cerebellar cortex and nuclei. Behav. Neural Biol. 60, 172-185.

Gruart, A., Guillazo-Blanch, G., Fernandez-Mas, R., Jimenez-Diaz, L., and Delgado-Garcia, J. M. (2000). Cerebellar posterior interpositus nucleus as an enhancer of classically conditioned eyelid responses in alert cats. J. Neurophysiol. 84, 2680-2690.

Gruart, A., Pastor, A. M., Armengol, J. A., and Delgado-Garcia, J. M. (1997). Involvement of cerebellar cortex and nuclei in the genesis and control of unconditioned and conditioned eyelid motor responses. Prog. Brain Res. 114, 511-528. 
Han, J. H., Kushner, S. A., Yiu, A. P., Cole, C. J., Matynia, A., Brown, R. A., Neve, R. L., Guzowski, J. F., Silva, A. J., and Josselyn, S. A. (2007). Neuronal competition and selection during memory formation. Science 316, 457-460.

Hesslow, G. (1994). Correspondence between climbing fibre input and motor output in eyeblink-related areas in cat cerebellar cortex. J. Physiol. (Lond.) 476, 229-244.

Hoehler, F. K., and Thompson, R. F. (1980). Effect of the interstimulus (CS-UCS) interval on hippocampal unit activity during classical conditioning of the nictitating membrane response of the rabbit (Oryctolagus cuniculus). J. Comp. Physiol. Psychol. 94, 201-215.

Holstege, G., van Ham, J. J., and Tan, J. (1986). Afferent projections to the orbicularis oculi motoneuronal cell group. An autoradiographical tracing study in the cat. Brain Res. 374, 306-320.

Humeau, Y., Reisel, D., Johnson, A. W., Borchardt, T., Jensen, V., Gebhardt, C., Bosch, V., Gass, P., Bannerman, D. M., Good, M.A., Hvalby, O., Sprengel, R., and Luthi, A. (2007). A pathwayspecific function for different AMPA receptor subunits in amygdala longterm potentiation and fear conditioning. J. Neurosci. 27, 10947-10956.

Ito, M., Sakurai, M., and Tongroach, P. (1982). Climbing fibre induced depression of both mossy fibre responsiveness and glutamate sensitivity of cerebellar Purkinje cells. J. Physiol. 324, 113-134.

Ivarsson, M., and Svensson, P. (2000). Conditioned eyeblink response consists of two distinct components. J. Neurophysiol. 83, 796-807.

Jirenhed, D.A., Bengtsson, F., and Hesslow, G. (2007). Acquisition, extinction, and reacquisition of a cerebellar cortical memory trace. J. Neurosci. 27, 2493-2502.

Killcross, S., Robbins, T. W., and Everitt, B. J. (1997). Different types of fearconditioned behaviour mediated by separate nuclei within amygdala. Nature 388, 377-380.

Kim, J. J., and Fanselow, M. S. (1992). Modality-specific retrograde amnesia of fear. Science 256, 675-677.

Kim,M., and Davis, M. (1993). Electrolytic lesions of the amygdala block acquisition and expression of fear-potentiated startle even with extensive training but do not prevent reacquisition. Behav. Neurosci. 107, 580-595.

Kishimoto, Y., Suzuki, M., Kawahara, S., and Kirino, Y.(2001a).Age-dependent impairment of delay and trace eyeblink conditioning in mice. Neuroreport 12 , 3349-3352.

Kishimoto, Y., Kawahara, S., Fujimichi, R., Mori, H., Mishina, M., and Kirino, Y. (2001b). Impairment of eyeblink conditioning in GluRdelta2-mutant mice depends on the temporal overlap between conditioned and unconditioned stimuli. Eur. J. Neurosci. 14, 1515-1521.

Kishimoto, Y., Fujimichi, R., Araishi, K., Kawahara, S., Kano, M., Aiba, A., and Kirino, Y. (2002). mGluR1 in cerebellar Purkinje cells is required for normal association of temporally contiguous stimuli in classical conditioning. Eur. J. Neurosci. 16, 2416-2424.

Kleim, J. A., Freeman, J. H. Jr., Bruneau, R., Nolan, B. C., Cooper, N. R., Zook, A., and Walters, D. (2002). Synapse formation is associated with memory storage in the cerebellum. Proc. Natl. Acad. Sci. U.S.A. 99, 13228-13231.

Koch, M. (1999). The neurobiology of startle. Prog. Neurobiol. 59, 107-128.

Koekkoek, S. K., Hulscher, H.C., Dortland, B. R., Hensbroek, R. A., Elgersma, Y., Ruigrok, T. J., and De Zeeuw, C. I. (2003). Cerebellar LTD and learningdependent timing of conditioned eyelid responses. Science 301, 1736-1739.

Koekkoek,S.K.,Yamaguchi, K., Milojkovic, B. A., Dortland, B. R., Ruigrok, T. J., Maex, R., De Graaf, W., Smit, A. E., VanderWerf, F., Bakker, C. E., Willemsen, R., Ikeda, T., Kakizawa, S., Onodera, K., Nelson, D. L., Mientjes, E., Joosten, M., De Schutter, E., Oostra, B. A., Ito, M., and De Zeeuw, C. I. (2005). Deletion of FMR1 in Purkinje cells enhances parallel fiber LTD, enlarges spines, and attenuates cerebellar eyelid conditioning in Fragile X syndrome. Neuron 47, 339-352.

Koekkoek, S. K. E., Den Ouden, W. L., Perry, G., Highstein, S. M., and De Zeeuw, C.I.(2002).Monitoring kinetic and frequency-domain properties of eyelid responses in mice with magnetic distance measurement technique. J. Neurophysiol. 88, 2124-2133.

Krase, W., Koch, M., and Schnitzler, H. U. (1993). Glutamate antagonists in the reticular formation reduce the acoustic startle response. Neuroreport 4, 13-16.

Lavond, D. G., and Steinmetz, J. E. (1989). Acquisition of classical conditioning without cerebellar cortex. Behav. Brain Res. 33:113-164.

LeDoux, J. E. (2000). Emotion circuits in the brain. Annu. Rev. Neurosci. 23, 155-184.

LeDoux, J. E., Cicchetti, P., Xagoraris, A., and Romanski, L. M. (1990). The lateral amygdaloid nucleus: sensory interface of the amygdala in fear conditioning. J. Neurosci. 10, 1062-1069.

Ledoux, J. E., Ruggiero, D. A., Forest, R., Stornetta, R., and Reis, D. J. (1987). Topographic organization of convergent projections to the thalamus from the inferior colliculus and spinal cord in the rat. J. Comp. Neurol. 264, 123-146.

Lee, K. H., Chatila, T. A., Ram, R. A., and Thompson, R. F. (2009). Impaired memory of eyeblink conditioning in
CaMKIV KO mice. Behav. Neurosci. $123,438-442$.

Lee, T., and Kim, J. J. (2004). Differential effects of cerebellar, amygdalar, and hippocampal lesions on classical eyeblink conditioning in rats. J. Neurosci. 24, 3242-3250.

Lennartz,W. (1992). Analysis of response systems in Pavlovian conditioning reveals rapidly versus slowly acquired conditioned responses: Support for two factors, implications for behavior and neurobiology. Psychobiology 20, 93-119.

Lingenhohl, K., and Friauf, E. (1994). Giant neurons in the rat reticular formation: a sensorimotor interface in the elementary acoustic startle circuit? J. Neurosci. 14, 1176-1194.

Luddens, H., Pritchett, D. B., Kohler, M., Killisch, I., Keinanen, K., Monyer, H., Sprengel, R., and Seeburg, P.H. (1990). Cerebellar GABAA receptor selective for a behavioural alcohol antagonist. Nature 346, 648-651.

Marr, D. (1969). A theory of cerebellar cortex. J. Physiol. 202, 437-470.

Mauk,M.D.,Steinmetz,J.E., and Thompson, R.F.(1986).Classical conditioning using stimulation of the inferior olive as the unconditioned stimulus. Proc. Natl. Acad. Sci. U.S.A. 83, 5349-5353.

McCormick, D. A., Clark, G. A., Lavond, D. G., and Thompson, R. F. (1982). Initial localization of the memory trace for a basic form of learning. Proc. Natl. Acad. Sci. U.S.A. 79, 2731-2735.

McCormick, D. A., Lavond, D. G., Clark, G. A., Kettner, R. E., Rising, C. E., and Thompson, R. F. (1981). The engram found? Role of the cerebellum in classical conditioning of nictitating membrane and eyelid responses. Bull. Psychon. Soc. 18, 103-105.

McCormick, D. A., Steinmetz, J. E., and Thompson, R. F. (1985). Lesions of the inferior olivary complex cause extinction of the classically conditioned eyeblink response. Brain Res. 359, 120-130.

McLean,P.J.,Shpektor,D., Bandyopadhyay, S., Russek, S. J., and Farb, D. H. (2000). A minimal promoter for the GABA(A) receptor alpha6-subunit gene controls tissue specificity. J. Neurochem. 74, 1858-1869.

Medina, J. F., Christopher Repa, J., Mauk, M. D., and LeDoux, J. E. (2002). Parallels between cerebellum- and amygdala-dependent conditioning. Nat. Rev. Neurosci. 3, 122-131.

Mihailoff, G. A., Kosinski, R. J., Azizi, S. A., and Border, B. G. (1989). Survey of noncortical afferent projections to the basilar pontine nuclei: a retrograde tracing study in the rat. J. Comp. Neurol. 282, 617-643.

Mintz, M., and Wang-Ninio, Y. (2001). Two-stage theory of conditioning: involvement of the cerebellum and the amygdala. Brain Res. 897, 150-156.
Miyata, M., Kim, H. T., Hashimoto, K., Lee, T. K., Cho, S. Y., Jiang, H., Wu, Y., Jun, K., Wu, D., Kano, M., and Shin, H. S. (2001). Deficient long-term synaptic depression in the rostral cerebellum correlated with impaired motor learning in phospholipase C beta4 mutant mice. Eur. J. Neurosci. 13, 1945-1954.

Morcuende, S., Delgado-Garcia, J. M., and Ugolini, G. (2002). Neuronal premotor networks involved in eyelid responses: retrograde transneuronal tracing with rabies virus from the orbicularis oculi muscle in the rat. $J$. Neurosci. 22, 8808-8818.

Muramoto, K., Ono, T., Nishijo, H., and Fukuda, M. (1993). Rat amygdaloid neuron responses during auditory discrimination. Neuroscience 52 , 621-636.

Neufeld, M., and Mintz, M. (2001). Involvement of the amygdala in classical conditioning of eyeblink response in the rat. Brain Res. 889, 112-117.

Oberdick, J., Smeyne, R. J., Mann, J. R., Zackson, S., and Morgan, J. I. (1990). A promoter that drives transgene expression in cerebellar Purkinje and retinal bipolar neurons. Science 248, 223-226.

Ohyama, T., and Mauk, M. (2001). Latent acquisition of timed responses in cerebellar cortex. J. Neurosci. 21, 682-690.

Ohyama, T., Nores, W. L., Medina, J. F., Riusech, F.A., and Mauk, M.D. (2006). Learning-induced plasticity in deep cerebellar nucleus. J. Neurosci. 26, 12656-12663.

Pare,D.,Quirk, G. J., and Ledoux,J.E. (2004). Newvistas on amygdala networks in conditioned fear. J. Neurophysiol. 92, 1-9.

Parenti, R., Zappala, A., Serapide, M. F., Panto, M. R., and Cicirata, F. (2002). Projections of the basilar pontine nuclei and nucleus reticularis tegmenti pontis to the cerebellar nuclei of the rat. J. Comp. Neurol. 452, 115-127.

Pavlov, I. P. (1927). Conditioned Reflexes, An investigation of the physiological activity of the cerebral cortex, Translated and edited by G. V. Anrep, New York, Dover Publications.

Paylor, R., and Crawley, J. N. (1997). Inbred strain differences in prepulse inhibition of the mouse startle response. Psychopharmacology (Berl.) 132, 169-180.

Pellegrini, J. J., Horn, A. K., and Evinger, C. (1995). The trigeminally evoked blink reflex. I. Neuronal circuits. Exp. Brain Res. 107, 166-180.

Perrett, S. P., Ruiz, B. P., and Mauk, M. D. (1993). Cerebellar cortex lesions disrupt learning-dependent timing of conditioned eyelid responses. $J$. Neurosci. 13, 1708-1718.

Pilz, P. K., Caeser, M., and Ostwald, J. (1988). Comparative threshold studies of the acoustic pinna, jaw and startle reflex in the rat. Physiol. Behav. 43, 411-415. 
Pilz, P. K., Schnitzler, H. U., and Menne, D. (1987). Acoustic startle threshold of the albino rat (Rattus norvegicus). J. Comp. Psychol. 101, 67-72.

Pitkanen, A., Savander, V., and LeDoux, J. E. (1997). Organization of intraamygdaloid circuitries in the rat: an emerging framework for understanding functions of the amygdala. Trends Neurosci. 20, 517-523.

Poulet, J. F., and Petersen, C. C. (2008). Internal brain state regulates membrane potential synchrony in barrel cortex of behaving mice. Nature 454, 881-885.

Qiao, X., Chen, L., Gao, H., Bao, S., Hefti, F., Thompson, R. F., and Knusel, B. (1998). Cerebellar brain-derived neurotrophic factor-TrkB defect associated with impairment of eyeblink conditioning in Stargazer mutant mice. J. Neurosci. 18, 6990-6999.

Quirk, G. J., Repa, C., and LeDoux, J. E. (1995). Fear conditioning enhances short-latency auditory responses of lateral amygdala neurons: parallel recordings in the freely behaving rat. Neuron 15, 1029-1039.

Rasmussen, A., Jirenhed, D. A., and Hesslow, G. (2008). Simple and complex spike firing patterns in purkinje cells during classical conditioning. Cerebellum 7, 563-566.

Rescorla, R.A., and Solomon, R. L. (1967). Two-process learning theory: relationships between Pavlovian conditioning and instrumental learning. Psychol. Rev. 74, 151-182.

Richardson, R. T., and Thompson, R. F. (1984). Amygdaloid unit activity during classical conditioning of the nictitating membrane response in rabbit. Physiol. Behav. 32, 527-539.

Rogan, M. T., Staubli, U. V., and LeDoux, J.E. (1997). Fear conditioning induces associative long-term potentiation in the amygdala. Nature 390, 604-607.

Rosen, J. B., Hitchcock, J. M., Sananes, C. B., Miserendino, M. J., and Davis, M. (1991). A direct projection from the central nucleus of the amygdala to the acoustic startle pathway: anterograde and retrograde tracing studies. Behav. Neurosci. 105, 817-825.

Ruigrok, T. J., and Voogd, J. (2000). Organization of projections from the inferior olive to the cerebellar nuclei in the rat. J. Comp. Neurol. 426, 209-228.

Rumpel, S., LeDoux, J., Zador, A., and Malinow, R. (2005). Postsynaptic receptor trafficking underlying a form of associative learning. Science 308, 83-88.

Sacchetti, B., Scelfo, B., and Strata, P. (2005). The cerebellum: synaptic changes and fear conditioning. Neuroscientist. 11, 217-227.

Sacchetti, B.,Scelfo, B., and Strata,P.(2009). Cerebellum and emotional behaviour. Neuroscience 162, 756-762.

Sacchetti, B., Scelfo, B., Tempia, F., and Strata, P. (2004). Long-term synaptic changes induced in the cerebellar cortex by fear conditioning. Neuron 42, 973-982.

Sakamoto, T., and Endo, S. (2008). GABAA receptors in deep cerebellar nuclei play important roles in mouse eyeblink conditioning. Brain Res. 1230, 125-137.

Sanchez, C. (2003). Stress-induced vocalisation in adult animals. A valid model of anxiety? Eur. J. Pharmacol. 463, 133-143.

Scelfo, B., Sacchetti, B., and Strata, P. (2008). Learning-related long-term potentiation of inhibitory synapses in the cerebellar cortex. Proc. Natl. Acad. Sci. U.S.A. 105, 769-774.

Schmaltz, L. W., and Theios, J. (1972). Acquisition and extinction of a classically conditioned response in hippocampectomized rabbits (Oryctolagus cuniculus). J. Comp. Physiol. Psychol. 79, 328-333.

Shi, C., and Davis, M. (1999). Pain pathways involved in fear conditioning measured with fear-potentiated startle: lesion studies. J. Neurosci. 19, 420-430.

Skelton, R. W. (1988). Bilateral cerebellar lesions disrupt conditioned eyelid responses in unrestrained rats. Behav. Neurosci. 102, 586-590.

Smith, D. R., Gallagher, M., and Stanton, M. E. (2007). Genetic background differences and nonassociative effects in mouse trace fear conditioning. Learn. Mem. 14, 597-605.

Steinmetz, J. E., Lavond, D. G., and Thompson, R. F. (1989). Classical conditioning in rabbits using pontine nucleus stimulation as a conditioned stimulus and inferior olive stimulation as an unconditioned stimulus. Synapse 3, 225-233.

Steinmetz, J. E., Logan, C. G., Rosen, D. J., Thompson, J. K., Lavond, D. G., and Thompson, R. F. (1987). Initial localization of the acoustic conditioned stimulus projection system to the cerebellum essential for classical eyelid conditioning. Proc. Natl. Acad. Sci. U.S.A. 84, 3531-3535.

Steinmetz, J. E., Rosen, D. J., Chapman, P. F., Lavond, D. G., and Thompson, R. F. (1986). Classical conditioning of the rabbit eyelid response with a mossyfiber stimulation CS: I. Pontine nuclei and middle cerebellar peduncle stimulation. Behav. Neurosci. 100, 878-887.

Supple, W. F. Jr., and Leaton, R. N. (1990). Lesions of the cerebellar vermis and cerebellar hemispheres: effects on heart rate conditioning in rats. Behav. Neurosci. 104, 934-947.

Svensson, P., Bengtsson, F., and Hesslow, G. (2006). Cerebellar inhibition of inferior olivary transmission in the decerebrate ferret. Exp. Brain Res. 168, 241-253.

Tracy, J. A., Thompson, J. K., Krupa, D. J., and Thompson, R. F. (1998). Evidence of plasticity in the pontocerebellar conditioned stimulus pathway during classical conditioning of the eyeblink response in the rabbit. Behav. Neurosci. 112, 267-285.

Trigo, J. A., Gruart, A., and DelgadoGarcia, J.M. (1999). Discharge profiles of abducens, accessory abducens, and orbicularis oculi motoneurons during reflex and conditioned blinks in alert cats. J. Neurophysiol. 81, 1666-1684.

Van Der Giessen, R. S., Koekkoek, S. K., van Dorp, S., De Gruijl, J. R., Cupido, A., Khosrovani, S., Dortland, B. Wellershaus, K., Degen, J., Deuchars, J., Fuchs, E. C., Monyer, H., Willecke, K., De Jeu, M. T., and De Zeeuw, C. I. (2008). Role of olivary electrical coupling in cerebellar motor learning Neuron 58, 599-612.

van Ham, J. J., and Yeo, C. H. (1996a). The central distribution of primary afferents from the external eyelids, conjunctiva, and cornea in the rabbit, studied using WGA-HRP and B-HRP as transganglionic tracers. Exp. Neurol. 142, 217-225.

van Ham, J. J., and Yeo, C. H. (1996b). Trigeminal inputs to eyeblink motoneurons in the rabbit. Exp. Neurol. 142, 244-257.

Villarreal, R. P., and Steinmetz, J. E. (2005). Neuroscience and learning: lessons from studying the involvement of a region of cerebellar cortex in eyeblink classical conditioning. J. Exp. Anal. Behav. 84, 631-652.

Vogel, R. W., Ewers, M., Ross, C., Gould, T. J., and Woodruff-Pak, D. S. (2002). Age-related impairment in the 250millisecond delay eyeblink classical conditioning procedure in $\mathrm{C} 57 \mathrm{BL} / 6$ mice. Learn. Mem. 9, 321-336.

Wada, N., Kishimoto, Y., Watanabe, D., Kano, M., Hirano, T., Funabiki, K. and Nakanishi, S. (2007). Conditioned eyeblink learning is formed and stored without cerebellar granule cell transmission. Proc. Natl. Acad. Sci. U.S.A. 104, 16690-16695.

Weeks, A. C., Connor, S., Hinchcliff, R. LeBoutillier, J. C., Thompson, R. F., and Petit, T. L. (2007). Eye-blink conditioning is associated with changes in synaptic ultrastructure in the rabbit interpositus nuclei. Learn. Mem. 14, 385-389.

Weisz, D. J., Harden, D. G., and Xiang, Z (1992). Effects of amygdala lesions on reflex facilitation and conditioned response acquisition during nictitating membrane response conditioning in rabbit. Behav. Neurosci. 106, 262-273.

Welsh, J. P. (1992). Changes in the motor pattern of learned and unlearned responses following cerebellar lesions: a kinematic analysis of the nictitating membrane reflex. Neuroscience 47 , 1-19.

Welsh, J. P., and Harvey, J. A. (1989). Cerebellar lesions and the nictitating membrane reflex: performance deficits of the conditioned and unconditioned response. J. Neurosci. 9, 299-311.

Welsh, J. P., Yamaguchi, H., Zeng, X. H., Kojo, M., Nakada, Y., Takagi, A., Sugimori, M., and Llinas, R. R. (2005). Normal motor learning during pharmacological prevention of Purkinje cell long-term depression. Proc. Natl. Acad. Sci. U.S.A. 102, 17166-17171.

Whalen, P. J., and Kapp, B. S. (1991). Contributions of the amygdaloid central nucleus to the modulation of the nictitating membrane reflex in the rabbit. Behav. Neurosci. 105, 141-153.

Won, J., and Silva, A. J. (2008). Molecular and cellular mechanisms of memory allocation in neuronetworks. Neurobiol Learn Mem 89, 285-292.

Woody, C. D., and Aou, S. (1999). Identification of differently timed motor components of conditioned blink responses. Brain Res. 836, 79-89.

Yeo, C. H., and Hardiman, M. J. (1992). Cerebellar cortex and eyeblink conditioning: a reexamination. Exp. Brain Res. 88, 623-638.

Yeo, C.H., Hardiman, M. J., and Glickstein, M. (1985). Classical conditioning of the nictitating membrane response of the rabbit. III. Connections of cerebellar lobule HVI. Exp. Brain Res. 60, 114-126.

Yeo, C. H., and Hesslow, G. (1998). Cerebellum and conditioned reflexes. Trends Cogn. Sci. 2, 322-330.

Yeomans, J. S., and Frankland, P. W. (1995). The acoustic startle reflex: neurons and connections. Brain Res. Brain Res. Rev. 21, 301-314.

Yuzaki, M. (2003). The delta2 glutamate receptor: 10 years later. Neurosci. Res. 46, 11-22.

Conflict of Interest Statement: The authors declare that the research was conducted in the absence of any commercial or financial relationships that could be construed as a potential conflict of interest.

Received: 21 July 2009; paper pending published: 21 August 2009; accepted: 29 November 2009; published online: 04 January 2010.

Citation: Boele HJ, Koekkoek SKE and De Zeeuw CI (2010) Cerebellar and extracerebellar involvement in mouse eyeblink conditioning: the ACDC model. Front. Cell. Neurosci. 3:19. doi: 10.3389/neuro.03.019.2009

Copyright (c) 2010 Boele, Koekkoek and De Zeeuw. This is an open-access article subject to an exclusive license agreement between the authors and the Frontiers Research Foundation, which permits unrestricted use, distribution, and reproduction in any medium, provided the original authors and source are credited. 